\title{
Are class size differences related to pupils' educational progress and classroom processes? Findings from the Institute of Education Class Size Study of children aged 5-7 Years
}

\author{
Peter Blatchford, Paul Bassett, Harvey Goldstein and \\ Clare Martin
}

Institute of Education, University of London

(revised March 2003)

Published as:

Blatchford, P., Bassett, P., Goldstein, H., and Martin. C. (2003) Are class size differences related to pupils' educational progress and classroom processes? Findings from the Institute of Education Class Size Study of children aged 5-7 Years. British Educational Research Journal, 29, 5, 709-730. Special Issue 'In Praise of Educational Research', Guest Editors: S. Gorrard, C. Taylor and K. Roberts

p.blatchford@ioe.ac.uk 


\section{Introduction}

One of the most enduring and vociferous debates in education over recent years has been about the educational advantages of small class sizes. Opinion has been consistently polarised between those who claim that small classes lead to a better quality of teaching and learning, and those who argue that the effects are likely to be modest at best and that there are other more cost effective initiatives. The first view is consistent with the view of many teachers and was given support by the Tennessee STAR research study which employed a powerful design involving random allocation of pupils and teachers to three classes within schools: 1. small, 2. 'regular', and 3. 'regular' with teacher aide. Children were followed for four years from kindergarten to Grade 3. It was found that children in small classes performed better in literacy and maths, and that there were particular benefits for children from ethnic minorities (Finn and Achilles, 1999; Nye, Hedges and Konstantopoulos, 2000). Recently some academics have argued in support of smaller classes as a cornerstone of educational policy (Achilles, 1999; Wang and Finn, 2000). This view has led to costly class size reduction initiatives in a number of States in the USA, notably California, as well in other countries around the world. It is also reflected in the UK Government's commitment to a maximum of 30 in a class at reception and KS1 (5-7 years).

The second view has found expression in the opinions of politicians and policy makers, worried by the enormous costs involved in hiring extra teachers. In the UK, the Government agency OFSTED (1995), on the basis of inspectors' reports, concluded that class size made little difference and this was used by Government ministers of the day to support no change in investment in smaller classes. This sceptical view of the effect of class size has also been taken by academics like Slavin (1989) and Hanushek (1999) who have argued in support of alternative uses of funding, e.g., teacher training.

The debate shows no signs of being settled, and the need for research evidence to inform policy is still pressing. Even though in the UK there is a cap on class sizes above 30 in the early years, a recent OECD report has shown that class sizes and pupil teacher ratios in the UK are still amongst the highest in terms of international comparisons (Education at a Glance, 2002). Moreover there is still a lot of variability in class sizes. Many teachers would consider that 29 children in a class, when aged 5-7 years, is still too many.

There is a need to distinguish between the effects of class size and pupil teacher ratios, which are allied but distinct entities (Blatchford, Goldstein and Mortimore, 1998). Put simply, is a class of 30 with two adults equivalent to two small classes of 15? If so then this would mean that it is the number of teachers to children that is crucial rather than the size of class. However, it may be, as argued by Wang and Finn (2000) that there is something special about a small class. It may encourage more shared responsibility and less distraction, and this makes it different in kind, and not reducible to a simple ratio of children to teachers. Debate about the effects of class size differences has also, in the UK at least, become connected to the recent Government investment in more Teaching Assistants in classrooms. The drive to increase their numbers is controversial, with the teaching unions uneasy about what they see as a possible devaluation of the teacher's role. 
There is, then, a lot at stake, especially given the huge financial implications of reducing class sizes and deploying more staff. But it was our conclusion (Blatchford, Goldstein and Mortimore, 1998) that there was little research on class size in the UK and little reliable information about the effects of class size differences on pupils' educational attainments, still less on whether the number of children in the classroom affected processes such as teaching, learning and peer relations. There was also little information available in the UK on whether extra support staff in classes are beneficial, and whether it is more important in larger classes. Our aim was therefore to contribute in a substantial way to the class size debate by conducting a sustained enquiry into the educational consequences of class size and pupil adult ratio differences.

Our interest in the subject began in the early 1990s when Peter Mortimore, who was then the Director of the Institute of Education, and Peter Blatchford, were asked by the National Commission on Education to write a briefing document on the educational effects of class size differences (Mortimore and Blatchford, 1993). A main conclusion was that there was a wide gap between professional experience - i.e., that other things being equal smaller classes are better educationally - and research evidence, which was not clear. A main impetus for the research reported in this paper was an attempt to bridge this gap.

There were two aims. The first was to study the effect of class size differences on pupils' educational attainments. Our study was conceived in the context of our reviews of previous research (Blatchford, Goldstein and Mortimore, 1998; Goldstein and Blatchford, 1998) and our identification of limitations in research designs. In the UK, correlational studies that used cross sectional designs, that is, examined relationships between class size and children's achievements at one point in time, are difficult to interpret because of uncertainties over whether other factors (e.g., non-random allocation of pupils to classes) might confound the results. In contrast, the strength of the research design used in the STAR project is that by randomly allocating teachers and pupils to classes, it is in theory easier to draw unambiguous conclusions concerning the causal role of class size. The STAR project is an impressive and bold study, but we have identified several theoretical and practical difficulties with experimental designs like the STAR project (Goldstein and Blatchford, 1998, see also Grissmer, 1999, Hanushek, 1999, Mitchell et al, 1991, Prais, 1996), that suggested to us the value in using an alternative non- experimental design. It was our belief that it would be more productive to research class size effects by seeking to capture the complex world of education rather than control one feature of it. It would, in other words, be more valid to seek better understanding of the effects of class size differences by measuring and examining relationships between class size and other factors as they occurred naturally in schools, and to make adjustments for possibly relevant factors such as family income. Most importantly, in order to overcome problems of cross-sectional studies, the design would need to be longitudinal, in order to control for pupils' prior attainments. Previous research has shown that the strongest effect of class size differences is on the youngest children in school and so the design would need to include school entry measures. (The STAR project did not obtain school entry attainments, and so cannot verify the supposed random assignment of pupils to classes.) We felt this type of design would provide a valuable source of evidence for policy because it would be more authentic. We could, for example, examine class size effects across the full range of class sizes, not just a few selected sizes. This could be important for policy recommendations, for example, if there are certain class sizes, or class sizes below or above a certain number, which have 
stronger effects. A main feature of our study was, therefore, a longitudinal follow up study of a large sample of pupils from school entry, and the use of sophisticated statistical analyses able to analyse connections between class size and attainment.

It is now appreciated that perhaps the main gap in understanding of class size effects is in terms of classroom processes that might be involved (Anderson, 2000). The second aim, and main feature of the study, was to research in a systematic way the relationships between class size and classroom processes. We need research evidence on classroom processes that allows us to understand the possible negative effects of larger classes and the possible advantages of smaller classes. It is important to consider what advice can be given to teachers to help them maximise opportunities of small classes and ways of minimising problems in large classes. So as well as the relevance of research to decisions about educational resourcing there are important implications for educational practice.

There is not space here to give a full background to the types of classroom processes included (see Blatchford, in press, a). Each type of process has been dealt with separately in papers that are referred to below. Here we note that there were five main areas:

1.Within class groupings (e.g., the size and number of within class groups)

Two processes connected to the teacher:

2.Teaching (e.g., amount of individual teaching, procedural, social and disciplinary interactions)

3.Individual support for reading

And two processes connected to the children:

4.Pupil inattentiveness

5.Peer relations

Our reviews indicated difficulties associated with methods of data collection used in much previous research. Different studies have used various research techniques including teacher report and interviews, questionnaires completed by teachers, teacher accounts of time spent, and observation studies, and it is not always clear they are covering the same phenomena. Integration of findings across studies is therefore made difficult. A more serious problem is that methods used are not always clearly described or adequate. Much is relatively anecdotal and based on the reported experience of individual teachers. Though valuable, there are questions about the validity and generalisability of such views, especially given the fact that previous research has found discrepancies between teacher reports and classroom observation data (Shapson et al, 1980). Large-scale secondary analyses, such as those in Betts and Shkolnik, Rice, and Rice, 1999) are, in a technical sense, more reliable but have involved relatively crude, easily quantified, retrospective judgements of time allocation.

It seemed to us that one way to advance understanding of the connections between class size and teaching would be to use a multi-method approach. We felt it would help reconcile inconsistencies in previous research. We collected quantitative information that would enable us to address basic questions on relationships between class size and pupil adult ratios, on the one hand, and teacher time allocation, teacher and pupil behaviour in class and children's school attainments, on the other hand. But we also wanted a more qualitative assessment of relationships between class size and 
teaching and individual support for reading, and understanding of the contribution of Teaching Assistants, through the use of methods that captured practitioners' experiences, and through detailed case studies. We therefore deliberately sought to combine different methods of data collection. This was a third main feature of the study.

To date, publications from the study have been on relationships between class size and attainment over the reception year (Blatchford, Goldstein, Martin and Browne, 2002); class size and within class groupings (Blatchford, Baines, Kutnick and Martin, 2001); class size and teaching (Blatchford, Moriarty, Edmonds and Martin, 2002); class size and teacher's and pupils' behaviour (Blatchford, in press, b); class size and pupil attentiveness and peer relations (Blatchford, Edmonds and Martin, in press); as well as a book length treatment of the whole reception and KS1 study (Blatchford, in press, a). Our purpose in this paper is to integrate the main findings and highlight our main conclusions. We also take the opportunity to reflect on lessons we have learned from the research.

\section{Method}

Sample: Schools, classes and children

The Class Size Study followed for three years a large cohort of pupils who entered reception classes (4-5 years) in English schools during 1996/7, and a second separate cohort of pupils who entered reception classes one year later during 1997/8. The children were followed for the first three years of school, that is, through reception (45 years), Year 1 (5-6 years) and Year 2 (6-7 years).

Numbers of LEAs, schools, classes and pupils in each cohort at the start of the study are shown in Table 1.

Table 1: Numbers of LEAs, schools, classes and pupils in each cohort at the start of the study

\begin{tabular}{|l|l|l|}
\hline & \multicolumn{1}{|c|}{ Cohort 1 } & \multicolumn{1}{c|}{ Cohort 2 } \\
\hline Number of LEAs & 9 & 6 \\
\hline Number of Schools & 199 & 134 \\
\hline Number of Classes & 330 & 212 \\
\hline Number of Pupils & 7142 & 4244 \\
\hline
\end{tabular}

The research design involved random selection of schools within the participating LEAs. All children entering reception classes in a selected school during the year were included in the study. The schools in the study drew from a wide range of social backgrounds, and were situated in urban, suburban and rural areas. Further details on sample schools and children are in Blatchford (in press, a).

Data collection

Information on children, classes and teachers

Information was collected for each child on: term of entry, free school meal eligibility, age, ethnic background, pre-school attendance, English as an additional 
language, special needs status, and gender. Information was collected on classes in terms of class size (as on the school register, and also in terms of the number of children in the class at a given point in the term - called 'experienced' class size), and on adults present, in terms of three categories: whether they were teachers, staff other than teachers, and other adults (including, and mainly, parents). Information on teachers in the study was collected from self completed questionnaires and comprised: teacher age, number of years of teaching experience, number of years in the current school, noncontact time, professional training in teaching reading, language and mathematics), and self perceptions of stress and satisfaction with their job (see Blatchford, Martin, Moriarty, Bassett and Goldstein, 2002).

\section{Children's Attainments}

Information was collected when pupils entered school by means of the Avon Reception Entry Assessment (1996), which covers literacy and mathematics and comprises information from teacher ratings, based on classroom observations, and tasks completed by children. At the end of the Reception year, the Literacy Baseline component of the Reading Progress Test (2000) and a specially designed mathematics test were administered. At the end of Year 1 the children were given the Young's Group Reading and Mathematics tests, and at the end of Year 2 Government set National Curriculum assessments (SATs) were coded using a specially adapted protocol, which captured raw scores on a continuous scale (rather than the restricted range of levels used by the Government and schools when reporting results, which are of limited value for research purposes). See Blatchford (in press) for more information on the measures used.

\section{Within class groupings}

A classroom mapping procedure devised by Blatchford, Baines, Kutnick and Martin (2001) was used. This involved teachers, at the given time in the school day, identifying the number and size of groups in the class; the composition of the group in terms of its ability level and whether it was comprised of friends; whether adults were with the group; the type of interaction between children (e.g., whether working alone but on the same task, or working together to produce an end product); and the curriculum area and type of task being worked on. Taking the data on all classrooms resulted in 672 classes in 311 schools, and a data base comprising 3157 groupings in all. More details on the methods used can be found in Blatchford, Baines, Kutnick and Martin (2001) and Kutnick, Blatchford and Baines (2002).

In order to complement the numerical results we also collected more open-ended interpretive information on groups. There were two sources of data: case studies involving semi-structured interviews with teachers, which were structured around a number of key areas, and questionnaires completed by class teachers at the end of each school year (see below). Quotes from interviews and questionnaires were selected to represent and complement the numerical results.

\section{Teacher estimates of time allocation}

Teaching time allocation: Data came from termly questionnaires completed by class teachers. They were given a pre-selected set of activities and asked for a given half day session to estimate the time in minutes spent on each activity. The activities were grouped into two broad types: first, teaching activities (teaching/working with the whole class, working with an individual child, and working with a group of children); 
and, second, classroom management and other non-teaching activities (collecting dinner money, lining the class up, putting on coats, taking the register etc.). Teachers were also asked for estimates of time spend in various reading activities on the basis of which two measures were derived: frequency of reading aloud to an adult in school, and duration of time each child was heard to read by an adult. Data came from 279 reception classes, 207 Year 1 classes, and 118 Year 2 classes. Further details on the methodology can be found in Blatchford, Moriarty, Edmonds and Martin, 2002.

\section{Systematic observations}

The observation component involved a sub sample of children in 18 small (20 or under) and 21 large (30 and over) reception classes. The average in small classes was 19 , and in large classes 33. There was a sub sample of 6 children in each class and 235 children in all. We used a systematic observation schedule that had been developed in previous research (Tizard, Blatchford, Burke, Farquhar and Plewis, 1988) which involved observations in terms of 5-minute observation sheets divided into continuous 10 -second time samples. The schedule had categories describing how children behaved in three 'social modes': when with their teachers, when with other children, and when not interacting. Subcategories within each of these three modes covered work, procedural, social, and off-task activities. For full definitions and conventions of categories see Blatchford (in press,b).

Teachers' experiences of the effect of class size - data from end of year questionnaires Questionnaires sent out near the end of each school year asked teachers about their experiences and views on selected topics, e.g., whether class size differences affected teaching and learning over the year, and the contribution of other staff and adults in the classroom. We analysed questionnaires completed by 151 reception teachers (cohort 2), 208 year one teachers (cohort one), 130 year one teachers (cohort two), and 153 year two teachers (cohort one). The aim was to describe teachers' views and experiences in a thorough way by collecting information from a substantial number each year and by a careful analysis of the range and type of answers given. The analysis combined quantitative analysis of the prevalence of different categories of answers with illustrative and verbatim quotations from teachers' written answers (see Blatchford, Moriarty, Edmonds and Martin, 2002 for more details).

\section{Case studies of selected small and large classes}

Case studies were conducted to provide complementary information to that in other quantitative components of the study. The aim was to provide a more detailed portrayal of individual classes, which would provide the basis for a more interpretive and grounded analysis of factors relating to staff and adult deployment in class. Schools were selected with differing class size categories, i.e., large (30 and over), large medium (26-29), small medium (20-25), and small (under 20). There were two classes in each class size band in each year (Reception, Year 1 and Year 2), totalling 24 classes in all. Selected aspects of classroom learning and experience, expected to be connected to class size differences, were defined in advance, and then on the basis of field visits were refined into headings including grouping practices; classroom discipline; tasks and curriculum; teacher pupil interactions and knowledge of children; and pupil adjustment and peer relations

The method comprised whole class and selected child observations in terms of event sampling of significant events; semi-structured interviews with teachers and the head 
teacher; end of session/day comments and judgements by field workers; summative judgements by field workers, all organised in terms of the main headings. This component made use of experienced teachers as field workers. Quite deliberately, the aim was to marry aspects of systematic observation (which emphasises the objectivity of data), with professional and interpretative judgements by experienced teachers. For further details see Blatchford, Moriarty, Edmonds and Martin (2002).

\section{Pupil Behaviour Ratings (PBR)}

The PBR was developed at the Institute of Education and was based on other behaviour rating scales (particularly Ladd and Profilet's (1996) Child Behaviour Scale). Teachers completed a PBR for every child in the study. The PBR comprised over 50 items rated on a three-point scale ('certainly applies to this child', 'applies sometimes to this child', 'does not apply to this child'). Scores on conceptually and empirically linked items that made up a set of factors were added. The factors measured were hyperactive/distractible, aggressive, anxious/fearful, pro-social, asocial, and excluded. (See Blatchford, Edmonds and Martin, in press, for full details).

\section{Results}

\section{Classroom processes connected to class size differences}

We summarise the main results under three main headings.

\section{Within class groups}

For much of their time in UK primary schools children are seated and work in groups. The class and the group can be thought of as different environmental contexts, with the group level nested within the level of the whole class. Logically the two levels, that is class size and within class groups, have to be connected. If a teacher had 20 children in the class she could organise them into say four groups each with five children. Faced with a class of 32 she could divide her class into four groupings of eight pupils, but the size of group then becomes large. She could form eight groupings of four pupils but then the number of groups might be unwieldy. She might choose to teach the class as a whole but this might be of limited use, especially with very young children. In each case, as class size increases the number of groups or the size of groups must increase. But the conceptual, and educationally important, question concerns how, in practice, class size and within class groupings are connected. To our knowledge the connection between size of class and within class grouping practices has not been looked at systematically before.

Results are described in detail in Blatchford, Baines, Kutnick and Martin (2001). The predominant group size is 4-6 children, which indicates the ubiquity in these English primary schools of classroom organisation in terms of small groups. These were followed in frequency by larger groups of 7-10 and 11+ (which were mainly whole classes). The results showed that size of class and the number and size of groups were connected. Larger classes led to more and bigger groups in the class. In class sizes over 25 there is more likelihood of a pupil being in a large group of 7-10. The qualitative analyses indicated that larger groups were a less effective educational environment. Teachers' everyday experience was that with a large class there is often a difficult choice between larger or more numerous groups, and that larger groups, at least 
with children of this age group, could have an adverse effect on the amount and quality of teaching and the quality of pupils' work and concentration in these groups. Some teachers felt that it was group size rather than class size which more directly affected their teaching and classroom management. So while debate and research on class size differences has often been in terms of direct effects on attainments, it is important educationally to consider the mediating role of within class groupings.

\section{Effects on teachers: Class size and teaching}

It might be expected that one set of classroom processes affected by class size would be aspects of teaching. Our concern was with the interactive side of teaching - the momentby-moment interactions between children and teachers. In brief, we were informed by research on teaching or instructional time in promoting students' educational attainments, research on effective teaching, and research and thought on teaching influenced more by cognitive psychology and the role of scaffolding in effective teaching/tutoring. However, there has been little work that draws out the role that classroom environmental factors like class size might play in affecting classroom teaching. We were particularly interested in finding out whether large and small classes differed in terms of the amount of teacher-child contact and individual attention from teachers. We made use of four forms of data, i.e., teacher estimates of time; systematic observations of selected small and large classes; teachers' experiences of the effect of class size on teaching and learning; and case studies of selected small and large classes, conducted by field workers.

We found consistent relationships between class size and teaching. There is a wealth of information from this part of the study and full details can be found in Blatchford, Moriarty, Edmonds and Martin (2002). Here we concentrate on a few key results. Looking first at the teacher time estimates, the relationship between total percentage time in teaching (i.e., time teaching to individuals, groups and the whole class) and class size for the reception year is shown in Fig. 1. It can be seen that apart from a little upturn in the case of larger classes (there were few of these) the smaller the class the more teaching overall, or, conversely, the larger the class the less teaching. The result was statistically significant in the case of reception and $\mathrm{Y} 1$, and in the same direction but not significant at Y2.

Fig. 1. Relationship between class size and percentage teaching time in morning session (reception year) 


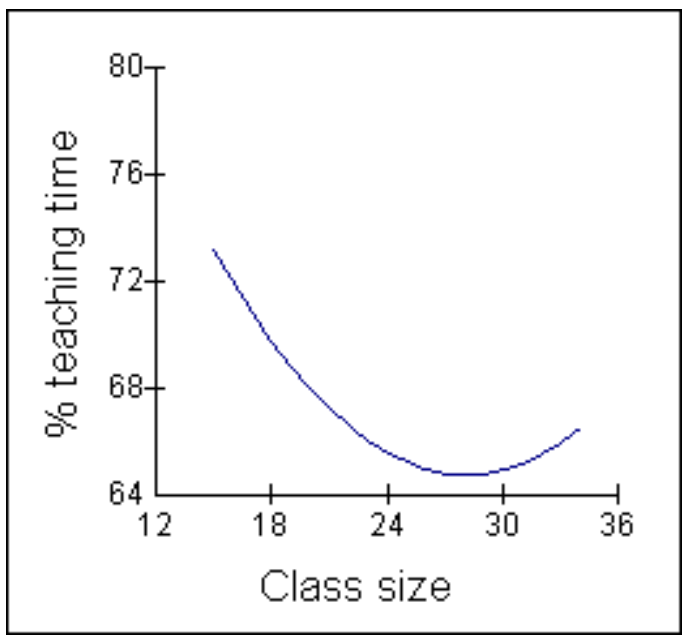

Because of the way the variables were defined, these results also mean that there was a correlation between size of class and non-teaching time, like register etc. That is, the larger the class the more non-teaching time.

In addition, some of the clearest findings were those concerning connections between class size and adults giving support to children as they read - a strategy that has been central in the teaching of reading to young children. The quantitative results from the time estimate data showed that in large classes children are heard to read by their teachers less often and for less time (see Blatchford, in press, a).

Results from the other main quantitative method, systematic observation, were perhaps the clearest of all. Differences between large and small classes in terms of time in the three main 'social modes' are shown in Fig. 2. It can be seen that children in smaller classes were observed interacting more with their teachers; on average in a small class children were observed 213 times with their teacher, as compared to 144 times in a large class. Conversely, in a large class children interacted more with each other and spent more time not interacting. All differences were statistically significant.

Fig. 2 about here 


\section{The Social Modes}

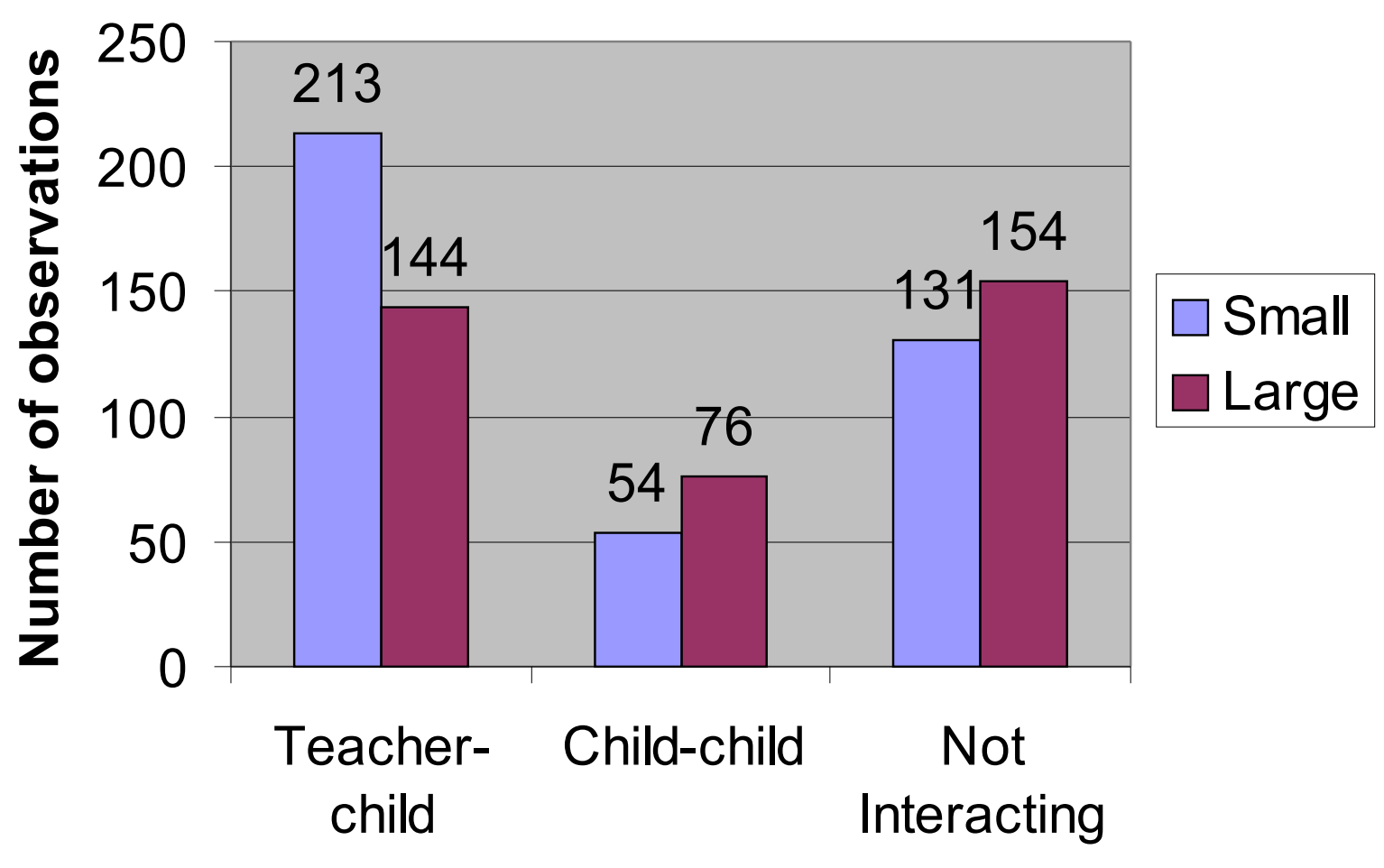


Looking more closely at the type of teacher behaviour toward pupils, the systematic observation results showed that in smaller classes children were more likely to interact with their teachers on a one-to-one basis; the child was more likely to be the focus of a teacher's attention, whether it was on a one to one basis (by definition the child was the focus), or in a group or the whole class; and that children in small classes also experienced more teaching Conversely, there was more procedural talk (e.g., about getting materials ready) in large classes. All these results were statistically significant (see Blatchford, Moriarty, Edmonds and Martin, 2002, and Blatchford, in press, b, for full details).

The results from the two more obviously quantitative components therefore showed that children in small classes were more likely to interact with their teachers, there was more teaching on a one-to-one basis, more times when children were the focus of a teacher's attention, and more teaching overall. In short, there was more teacher task time with pupils.

The qualitative data from end of year questionnaires and the case studies supported and complemented these quantitative data. In brief, they showed that in smaller classes there was more teacher support for learning, as reflected in the amount of individual attention paid to students, and in terms of the immediate, responsive, sustained and purposeful nature of teacher interactions with children, the depth of a teacher's knowledge about children, and sensitivity to individual children's needs. In addition, classroom management and control were easier.

Putting all the results together, from the four forms of data, we can sum up the relationships we find between class size and teaching as follows: in smaller classes there is 1 . more teacher task time with pupils, 2. more teacher support for learning, and 3. easier classroom management and control. Overall we propose that there is support for the notion that in smaller classes there is more likelihood of what we call TEACHER SUPPORT FOR LEARNING - more individualisation of teaching if you like, though this does not imply it has to be on a one-to-one basis - it could be in group or whole class contexts (see Blatchford, Moriarty, Edmonds and Martin, 2002, for a full account). Our results suggest that while small classes will not make a bad teacher better, they can allow teachers to be more effective; conversely large classes inevitably present teachers with difficulties and the need for compromises. Our results are consistent with other recent comments on relations between class size and teaching, and indicate that small classes can offer opportunities for teachers to teach better (Anderson, 2000) or, to use a different term, they can create facilitating conditions for teachers to teach and students to learn (Wang and Finn, 2000).

\section{Affective considerations: Compensatory efforts}

An additional comment can be made on the relationship between class size and teaching. Effective teaching may be possible in large classes, but this may be at some cost to teachers, for example, in terms of working that much harder, and in terms of eating away at spaces like breaks in the day. It may also affect a teacher's professional satisfaction and enthusiasm. This theme is taken up more fully in Moriarty, Edmonds, Blatchford and Martin (2001). This suggests that relations between class size and pupil outcomes may therefore be minimised because of teachers' level of commitment, driven by their 
professional self-perception. If this is true then relations between class size and outcomes are complicated by ways in which teachers may compensate for the expected negative effects - a nice example of how a simple model of causality does not work in real life!

\section{Effects on children}

We were interested in pupil social and behavioural adjustment in terms of two main components: inattentiveness/off-task behaviour and peer relations. Regardless of any connection with class size, studies of classroom processes related to pupil achievement, going back decades, support the view that a key aspect of educational success is attentiveness, or active learning time, time on task or some equivalent term (e.g., Creemers, 1994). We wanted to know more about the connection between inattentiveness and off task behaviour and class size. Common sense would suggest that with more children in the class there will be more potential for distraction, and more possibility of being off task. Finn and Achilles (1999) have expressed the connection between small classes and pupil attention or engagement in class perhaps most clearly. But again the research evidence was not clear. With regard to peer relations, there is a lot of evidence that difficulties with peers appear to be important in later personal adjustment and social functioning but a main point to make is that there is little research on the effects of contextual classroom factors like class size on peer social relations.

Our strongest prediction was that there would be a tendency as class size increased for children to show more signs of being inattentive and off task. We also predicted that there would be more signs of social difficulties between children as class size increased, in the form of more rejection and asocial behaviour, less prosocial behaviour, more signs of anxious behaviour, and more aggressive behaviour. We used two types of data: those from systematic observations and from the Pupil Behaviour Ratings (PBR).

The results showed three main ways in which class size affects children.

i. More active involvement with teachers

The observation results showed that in smaller classes children did not just receive more contacts from teachers, but also had a more active role themselves, in terms of more child initiations and responses to the teacher. This finding was supported by teacher reports and case studies (Blatchford, in press, a).

ii. Pupil inattentiveness and off task behaviour

Results from the systematic observations showed that children in large classes were twice as likely to be off task. This was evident in all three social modes: in contacts with their teachers they were less likely to attend to her and were more off task; with other children they were more likely to be actively off task; and when on their own they were more likely to be off task, especially in the passive form of being disengaged from allocated work. Results from the teacher completed Pupil Behaviour Ratings (PBR) were less clear, though there were modest but significant relationships between class size and distractibility; the larger the class the more distracted the children. See Blatchford, Edmonds and Martin (in press) for full details. These results were supported by qualitative analyses which showed that teachers found that in larger groups (more likely in larger classes) it was harder for pupils to concentrate (see above). 
There is then confirmation across both quantitative and qualitative results that children in large classes are likely to be more distracted from work and more often off task. These results offer support for the view of Finn and Achilles (1999) that one of the main effects of class size is on children's attentiveness in class.

\section{iii. Peer relations}

We have already seen from the systematic observation results that class size differences affect the balance between teacher-pupil and pupil-pupil interactions. Children in larger classes spend more time with each other (see Fig 2), and further analysis of individual child-child categories showed that this applied to interactions about work, about social matters, and also 'mucking about'. Social relations between children as revealed in the PBR were not strongly related to class size. There was no support for the expectation that relations between children would be worse in large classes. Indeed, we found that there was a slight though consistent tendency for worse peer relations, in terms of aggression and rejection of peers, in the smallest classes. Smaller classes may be better academically but not necessarily socially. It needs to be stressed, however, that this finding needs further research and replication. A full account of connections between class size and inattentiveness and peer relations can be found in Blatchford, Edmonds and Martin (in press).

A summary model of the effect of class size differences on classroom processes and outcomes

Our research suggests that it is not likely, or realistic, to think that one theory or conceptual framework will account for effects. Class size effects are, in other words, not singular but multiple. Accordingly, we will need multiple theoretical or conceptual frameworks to account for these effects and to judge their implications, e.g., connected to teaching, pupil attentiveness and social relations. Further, the different effects may have conflicting outcomes, e.g., in the sense that smaller classes can lead to positive academic outcomes but problematic social effects. Picking up on the point just made about teachers' compensatory efforts suggests a further complication, in that there may be not only multiple effects but different effects can themselves affect each other, so that, for example, teachers may make extra efforts to hear children read, e.g., during the lunch break, because a larger class has limited the time available for this activity during lesson time.

It would therefore be difficult to capture all the possible complexities involved, but as a way of summarising and integrating the quantitative and qualitative data on classroom processes, that are related to class size differences, we have prepared Figure 3.

Fig 3 about here 


\section{Teacher task time with pupils}

2. Teacher/Individual support for learning

3. Classroom management \& control

4. Teacher stress/compensatory efforts

\section{Size and Number of} Within Class Groups

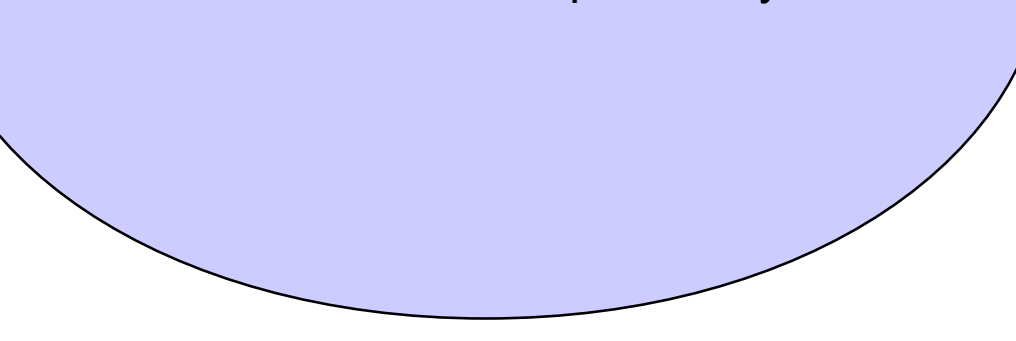

\section{Class Size Differences}

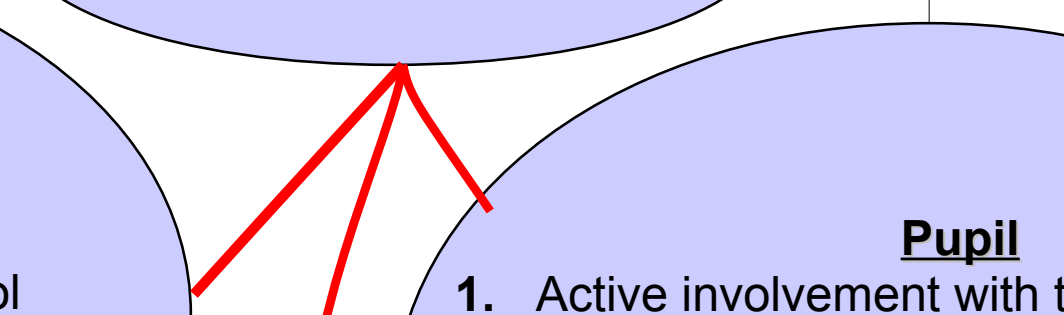

1. Active involvement with teacher

2. Pupil attentiveness/Off-task behaviour

3. Peer relations

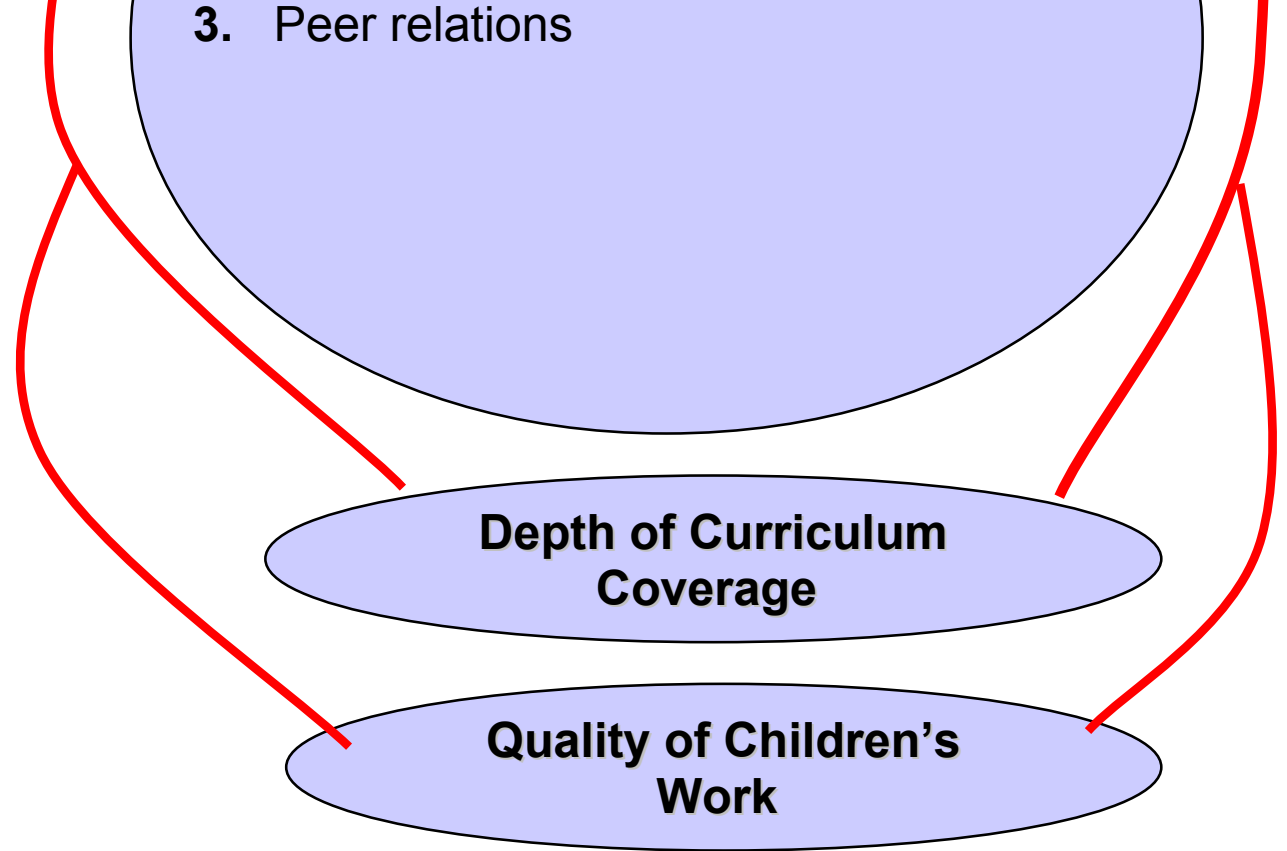


Figure 3 is designed to be a descriptive summary of findings rather than an exact portrayal of statistical relationships or causal paths. Some connections are likely to be stronger than others, for example, because they are suggested by both quantitative and qualitative analyses. This is not meant to be the 'right' model but rather a best description of relationships found in our study. It can be seen that as well as connections already discussed, we have also added two areas suggested by our questionnaire and case study data (see Blatchford, in press,a) but which need further verification: the depth of curriculum coverage and the quality of student work.

\section{$\underline{\text { Class size and pupil attainment }}$}

In this section selected results are highlighted. A full presentation and discussion can be found in Blatchford, Bassett, Goldstein and Martin (submitted)

Statistical methods: The effect of class size upon progress in literacy and mathematics was examined for each of the three years separately. The models controlled for the pupils' attainment scores in previous school years, so that the results more accurately reflected the progress made during the course of the year. Adjustments were also made for characteristics of the children, class and teacher and changes in class size from previous years. The original scores were transformed to normal scores so that one unit of the outcome represented one standard deviation of the original score. All analyses used multilevel models (Goldstein, 1995), to take account of the structure of the data, with pupils contained within classes, which were nested within schools.

\section{Reception Year - Literacy}

The results showed that the relationship between class size and reception year progress in literacy varied for pupils of differing baseline attainment, and so these are presented separately in Figure 4.

Figure 4: Relationship between Reception year class size and literacy progress (adjusted for school entry scores).

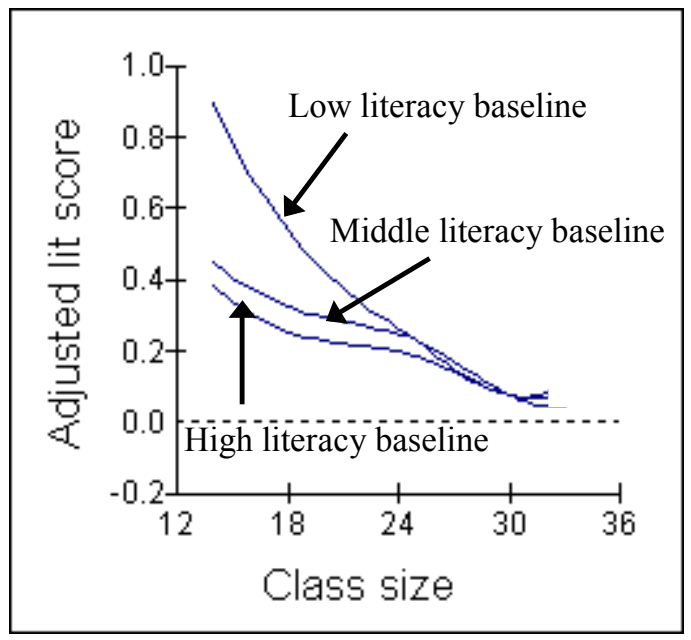

Pupils were split into three ability groups, based on their pre-reception year literacy scores (bottom 25\%, middle 50\% and top 25\%). There was a strong and statistically 
significant increase in attainment for all three groups, though there was a larger effect for pupils with lower baseline attainment. A reduction in class size from 30 to 20 pupils resulted in an increase in attainment of approximately 0.35 standard deviations for the low attainers, 0.2 standard deviations for the middle attainers, and 0.15 standard deviations for the high attainers.

\section{Reception year - Mathematics}

In contrast to literacy attainment, there was no evidence that the effects of class size varied between the three different baseline attainment groups. The relationship between class size and mathematics progress is shown in Figure 5. There is a roughly linear (straight line) relationship between the two variables, which was found to be highly statistically significant $(\mathrm{p}<0.001)$. A reduction in class size from 30 to 20 pupils resulted in an increase in attainment of approximately 0.25 standard deviations.

Figure 5: Relationship between class size and mathematics attainment in Reception (adjusted for school entry scores).

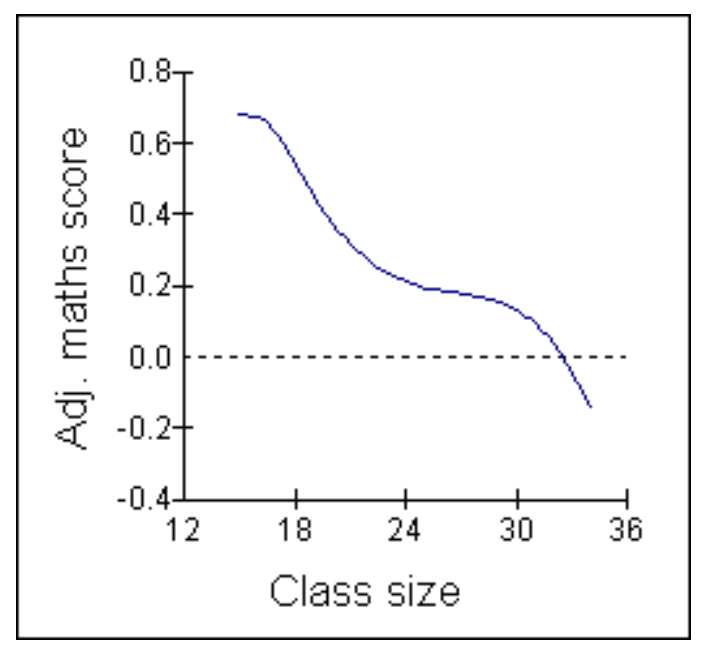

Year $1 \&$ Year 2 - Literacy \& Mathematics

The results of the Year 1 and Year 2 data indicated that class size in each year was not found to be related to progress in either literacy or mathematics.

The effect of reception year class size on Year 1 results - Literacy

We examined whether the benefits gained by small classes in the Reception year were sustained during Year 1. In these analyses, Year 1 literacy scores were used as the outcome variable, and Reception year class size was used as the main explanatory variable. The end of reception scores were included, so that the progress of pupils over Year 1 was examined. The majority of pupils moved to similar sized classes, but there were some who moved to either smaller or larger classes. In order to see whether change in class size was important, pupils were split into three groups: first, the $25 \%$ of pupils who had the biggest change to smaller classes, second, the middle $50 \%$ who moved to similar sized classes, and third, the $25 \%$ of pupils who had the biggest change to larger classes. Results showed that there was a significant interaction between class size and change in class size group $(\mathrm{p}=0.003)$, indicating 
that the effect of reception year class sizes on progress in year 1 literacy is dependent on the change in class size between the two years. The relationship between Year 1 literacy and reception year class size is shown for the three groups separately in Figure 6.

Figure 6: Relationship between Reception class size and literacy progress in Year 1.

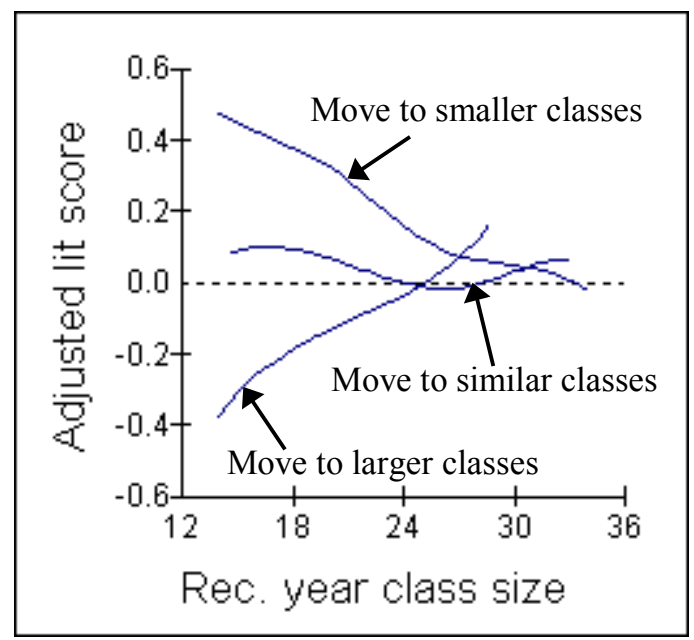

These results show that the progress made in small classes in reception is maintained in Year 1 for pupils who move to smaller or similar sized classes, but that moving to a larger class between the two years loses the benefit of small reception year classes. In addition to the interaction between the effect of reception year class size and change in class size between reception and Year 1, there was found to be an effect of moving to classes of different sizes between reception and Year 1 on both literacy and mathematics progress in Year 1. There was therefore evidence of what might be called a 'disruption effect', in that pupils' progress over Year 1 was adversely affected by moving to a different sized class, especially a larger one. There was less change in class size between Year 1 and Year 2 and there were no effects of change in class size on attainment in Year 2.

Effect of Reception year class size on Year 1 - mathematics

The results showed that pupils in larger Reception year classes made more progress during Year 1, and the gains made in the Reception year have been greatly eroded by the end of Year 1.

\section{Effect of Reception year class size on Year 2 results}

The results indicated the gains in literacy attainment in Reception that were maintained for pupils not moving between larger classes between Reception and Year 1 were lost during Year 2. The gains had been lost in mathematics by the end of Year 1 .

Role of classroom processes in explaining Reception year class size effects The relationships between class size and process variables have been summarised above. However, the relationships between Reception year class size and both literacy and mathematics attainment were found to be relatively unchanged for the additional adjustments for those process variables included in the statistical models. Therefore it 
appears that little or none of the class size effects can be "explained" by the process variables.

The effect of staff and adults, in addition to the teacher, on educational progress The effect of additional staff and additional adults on pupils' educational progress in maths and literacy was examined. The results can be easily summarised. There was no evidence for any year for either literacy or maths that additional staff or additional adults in the class had an effect on children's progress.

Results for the second cohort produced similar results.

\section{Conclusions}

\section{$\underline{\text { Class size and classroom processes }}$}

In this study we found that class size is related to several classroom processes. We argue that the effects of class size are likely to be multiple not singular and presented Fig 3 to summarise the relationships we found on the basis of integrating the quantitative and qualitative data. The relationships are taken up more fully in Blatchford (in press,a). Here we note that we found little evidence from the full statistical analysis that the classroom processes had a mediating role in the relation between class size and achievement. To take an example, although class size is related to teaching time, it is not possible to say on the basis of our statistical results that teaching time mediates the effect of class size differences on attainment. This is in a sense a disappointing result though methodological features of our study might have underestimated some effects. Some of the 'process' measures, e.g., on teaching time, were relatively broad and measured not at the child but the more general class level. They are therefore less sensitive than measures on the individual child.

Having said this, the statistical analyses have been helpful in narrowing down the likely processes connected to both class size and progress, and this study has, therefore, helped identify the variables that could be fruitfully examined in future research. The more qualitative analyses have also indicated aspects possibly linked with class size that could be followed up. There are, therefore, a number of leads from this study concerning where future research should be best targeted, in particular the aspects of teacher and pupil behaviour listed in Figure 3.

\section{$\underline{\text { Class size and children's educational attainment }}$}

The effect of class size on children's educational progress over the first year of school is impressive, even after adjusting for possible confounding factors. The effect is comparable to that reported by the experimental STAR project (see Blatchford, Bassett, Goldstein and Martin, submitted), and this trend is therefore confirmed by both experimental and non-experimental research designs. Several main points can be made about the relationship between class size and children's attainment. 
The Age or Year Group of children is important

Our results show how vital it is to take account of the age of the child when considering class size effects. The effects are most obvious in the first year in school - the Reception year. This is consistent with the STAR project (Finn and Achilles, 1999). There seem to be clear policy implications. There is a clear case for small class sizes in the reception year. The UK Government's policy of a maximum class size at 30 is to be welcomed but our results show where resources should be further targeted. There is also support for the view that small classes and class size reduction initiatives are best seen as a policy of prevention but not remediation, in the sense that the evidence supports the use of small classes immediately after entry to school, but there is no evidence that small classes introduced later in children's school lives are as effective.

Who benefits?

Small classes appear to work best in literacy for children who are most in need academically, and who thus have most ground to make up. These findings further suggest where targeting of resources (in this case small classes) might be best directed.

\section{Benefits for how long?}

The effects of class size in the reception year are still evident on literacy progress at the end of the second year of school (Year 1), though by the end of the third year the effects are not clear. There were no clear longer-term effects of class size differences on mathematics achievement. In one sense this indicates that the early benefits of smaller classes on literacy achievement 'wash out' after two years in school, though it needs to be remembered that the children in this study (in contrast with the STAR project) were not restricted in terms of which size of class they moved to from year to year.

\section{'Disruption' effect}

In this study we were able to capture the 'real world' of class sizes as they occurred in schools, and so we were able to analyse more precisely the influence of changes in class size from year to year. Findings here are important. The biggest changes in class size took place between reception and Year 1 and we found an important 'disruption' effect on children's educational progress as a consequence. Moving to a class of a different size, especially a larger class, was disruptive. But we also found that the effect of small reception classes carried over into Year 1 only when children moved into a similar or smaller class. The policy implication of this result seems to be that, in addition to smaller classes in the Reception year, it is advisable to maintain smaller classes where possible, and to seek to ensure stability in class sizes across years.

There may be longer term effects of class size differences, beyond that evident from study of the first three years of school, and in current research we are following the same children over the next stage of their schooling, i.e., 7-11 years (KS2), and documenting both class sizes and educational achievement. As children develop and there are curriculum and other changes, there may also be different relationships between class size and classroom processes. We are therefore repeating case studies and systematic observations in order to see whether the effects of class size on teaching and child behaviour are still evident at the end of children's primary schooling, as well as at the beginning. 
An optimum class size?

Is there a 'best' class size? Do benefits from small classes only appear if reduced below 20, as US research suggests? One advantage of our research, in contrast to class size reduction experiments, like the STAR project, is that we did not restrict class sizes, and we can therefore make judgements about the effects of the full range of class sizes found in our schools. Our results suggest a complex picture when it comes to judgements about optimum class sizes. In maths, during the first year, there are benefits resulting from decreases in class size across the full range of class sizes, not just below 20 in a class. However, in the case of literacy, the size of class below which benefits are most marked varies according to the child's level of attainment prior to school entry, as we have just seen. Effects for the lowest attainers are most marked when they are 25 and smaller. In general it is probably over simplistic to talk about optimal class size in an exact way. Teachers' judgements about preferred class sizes are likely to be affected by what they have experienced and what they perceive as realistically achievable.

Judgements are also likely to be affected by culturally bound views about teaching and about learning, and for these reasons it would not be surprising if views differed between countries. We need, therefore, to be careful about comparisons across countries and attempts to pin down an optimal class size.

\section{Class size and extra staff and adults}

There was no clear evidence for any year, for either literacy or maths, that additional staff or additional adults in the class had an effect on children's progress, and there was no apparent 'compensation' effect of having extra adults in the class. This result is consistent with the STAR project, where it was found that there was no compensatory effect of having extra staff in larger (regular) classes. It is also supported by other recent research (Finn, Gerber, Farber and Achilles, 2000). The consistency of results from these studies makes provocative reading. However, as reported in a separate paper (Blatchford, Martin, Moriarty, Bassett and Goldstein, 2002) we were able to go beyond statistical relationships between the presence of extra staff and students' achievement and look more closely and in a more rounded way at the contribution of teaching assistants, on the basis of teacher questionnaires and case studies. We found that teachers were largely positive about the contribution of teaching assistants but the case studies revealed considerable variation in their effectiveness, and it was this that was likely to account for the lack of clear associations with children's attainments.

\section{Dealing with class size differences: implications for teaching}

We have seen that a small class has the potential to allow teachers to provide more individualisation of instruction, so an important next step in this analysis concerns how the teacher DEALS with this classroom contextual feature, that is, with class size. She can deal with it inappropriately. Evertson and Randolph (1989) have offered a fascinating account of observations in STAR small classes. They argue that the adherence of teachers to established methods of reading and maths instruction (as well as the mandated curriculum in Tennessee, which emphasises basic skills) may have minimised differences between processes in small and regular classes. In a similar way, our case studies indicated one feature of smaller classes - a tendency to allow immediate feedback - could lead to frequent interruptions, and needs to be watched carefully by teachers. On the other hand a teacher can deal with small classes effectively. We have documented examples of teachers in small classes doing a 
marvellous job - with observers coming away inspired by the quality of teaching and children's educational experiences. In these classrooms teachers were taking full advantage of the extra opportunities for individual, focused and sustained attention provided by small classes. The benefits of having fewer children will not necessarily follow. Teachers have to work just as hard to manage learning effectively.

\section{$\underline{\text { Other contexts for learning - group work }}$}

One danger that should be warned against is to see all the benefits of smaller classes in terms of increased opportunities for individualised teaching. We need to be careful not to overlook the benefits that can stem from other contexts for learning. In particular there is no guarantee that smaller classes will automatically lead to more productive work in groups. We found that there was if anything less cooperative group work in smaller classes and that teachers did not seem to recognise the possible benefits of smaller classes for more productive group work (Blatchford, in press,a). There may be particular implications here for teachers in larger classes. We have seen that pupils are likely to interact more with each other in larger classes, and one way teachers might make the most of large classes is to consider helping the children toward effective group work. However, in parallel research we have found, at both primary and secondary school stages, that teachers had little faith in students' abilities to work in groups, and groups were not set up or prepared with a clear educational purpose. Students themselves were worried about working in groups (Blatchford, Kutnick, Clark, Macintyre and Baines, 2002). We argue that groups within the class should be considered not just in terms of increasing teacher attention to pupils, but in terms of taking seriously pupil selfdirected group work in classes. A teacher need not be a 'sage on the stage' at all times. Even in small classes she can afford to be a 'guide on the side'!

One implication of our results, also suggested by Galton et al (1996) is the value in designing teacher training programmes, both initial and continuing, which consider ways of adjusting productively to contextual features like class size. It is not, as some imply, a case of either supporting teacher training to improve teacher quality, or reducing class sizes. We need to consider both together, and ways of making the most of the opportunities of smaller classes and ways of dealing with large classes. There is an allied need to plan for the effective deployment of teaching assistants and other adults in educational settings.

\section{Reflections on the study}

Now that most of the data for the study have been analysed and the planned papers have been written it is possible to look back and ask what lessons have been learned. Some features of the study have proved to be sound. We believe the longitudinal design though expensive in time and funds was especially valuable. In the case of correlational, i.e., non-experimental designs, without random allocation, a longitudinal design is essential to make any judgments about causality. It allowed us to examine the effect of class size and extra adults, while controlling for previous factors, including prior levels of educational achievement. It allowed us to build changes in class size between years into our analyses. We also worked hard to build on existing expertise in multi-level modelling techniques and develop statistical models sophisticated enough to model the 
likely complex relationships between class size and pupils' educational progress, while controlling for likely confounding factors. One advance over previous research was the modelling and graphical representation of relationships throughout the distribution of class sizes. A simple linear relationship cannot be assumed.

There are a number of difficult issues involved in any comparison of non-experimental vs. experimental research designs, which cannot be entered into here. One of the potential problems with non-experimental designs is that there may be other possibly influential variables which have not been included in the analysis which might explain relationships between class size and outcome. This is a possibility the reader would need to bear in mind, though every effort was made to include likely factors. The use of previous attainments test scores makes it very unlikely that our results could be explained by the allocation of children of different abilities to different class sizes - a problem that bedevilled some earlier UK research (Blatchford, Goldstein and Mortimore, 1998). A connected issue concerns whether there was anything systematic about the allocation of teachers to classes of different sizes - for example that teachers allocated larger classes were more experienced or more effective. We did not measure directly quality of teaching in different classes and so we cannot be entirely sure about any differences between teachers in different classes. However, in separate analyses we have found no relationships between class size and a number of teacher characteristics, including age, length of teaching experience, participation in in-service training and a judgement by headteachers of teachers' effectiveness.

We feel that the use of a multi method approach to data collection was vindicated. Again the longitudinal nature of the research helped because it was possible to adapt methods in the light of emerging results so that methods became progressively compatible, internally consistent, and deliberately complementary. So, for example, results from the systematic observations during the reception year were clear about the importance of individualised instruction and the greater amount of peer interactions in larger classes, and these informed the questions asked in the end of year teacher questionnaires.

Methods were adjusted and fine-tuned in the light of early field visits and data analyses. Another connected feature was the presentation of early results to teachers involved in the first year of the research. We were able to discuss provisional findings with them and together work through some possible explanations and possibilities of changes to data collection techniques and additional information needed.

We avoided the choice of instruments/methods on the basis of apriori decisions about the appropriate way of combining qualitative and quantitative approaches. Rather, our choice was informed by debates in previous research and what methods of data collection seemed best able to address specific research questions and dimensions related to classroom processes considered important. In particular, in examining relations between class size and teaching, we feel even more strongly that there is considerable value in combining in the same study data that stems from classroom observation, teacher report, and informed fieldworker notes.

But there are difficult issues involved in the use of mixed method approaches, that require further attention. One issue concerns the way that different techniques are used together. Our approach was to develop methods that were deliberately complementary. An alternative approach, though, would be to use a particular method of data collection to test the claims from other forms of data. There are also problematic issues when it 
comes to establishing causal relations between class size, classroom processes and achievement, and this is likely to be exacerbated by the use of a mixed method approach. We have seen that one aim was to combine quantitative methods such as time estimates with methods more able to capture the individual situation in classes and give expression to teacher experience. We have in this paper been able to give scant expression to these richer forms of data, and this reflects difficulties involved when seeking to include them in analyses of causal relations. Clearly qualitative and more interpretative data have purposes other than establishing causality, but if it is agreed that there is value in integration then there is a need to think through more carefully ways in which this can take place, and this would include ways in which relatively fine grained data on classroom processes can be used in analyses of causal relations between a factor like class size and pupils' educational achievement and learning.

There are several limitations of this study. There may be other 'outcomes' and classroom processes, related to class size differences, that were not covered. Any study has to be selective and, although aspects of children's attainment and classroom processes were chosen carefully on the basis of previous research and our visits to schools, there may be other features that are important. In the case of child 'outcomes', we deliberately concentrated on the academic outcomes of literacy and maths, not the least because we believe they are important indicators. We did cover areas of child development other than attainment. We have, for example, seen that class size was related to student inattentiveness and this can be seen as a basic requirement for learning. We also found that work related interactions between children were affected by size of class. In the end of year reports from teachers and the case studies there were a number of suggestions of ways in which class size could be related to learning in a more general sense than academic attainment. But there are no doubt effects of class size differences on other aspects of children's work, for example, in terms of more creative and artistic areas, and in terms of other 'outcomes' like problem solving. Anecdotally we know that teachers feel that time devoted to literacy, numeracy and science means that there is now less time available for more creative and artistic activities, and this might be expected to be especially true in larger classes. There is a case for looking more systematically at dimensions we did not cover.

There is also the point that any kind of statistical analysis, no matter how sophisticated, rests on quantification, and it may be that some essential processes and their effects cannot be captured in this way. We have discussed this possibility elsewhere (Blatchford, Goldstein and Mortimore, 1998). It may be that a smaller class size allows a teacher to approach children in a more personalised and more humanistic way, but this would be hard to measure and then enter into statistical analysis!

Another potential limitation of the research is the time when it took place. All educational research is historically located and since it began there have been more recent initiatives, including the rearrangement of the stages of education for young pupils such that the 'reception' year (the year in school when children become 5 years) is now classified as the last year of the 'Foundation Stage'. There is not space here to enter into debate about this change but, whatever the merits or otherwise, the question we do need to address is whether it affects the interpretation of the research findings presented in this paper. It is difficult to answer this question with any certainty, not the least because we do not have systematic information on just how much change in reality there has been in the Reception year. However, the connection 
between class size and teacher support for learning, found in this research, is likely to be even more relevant when the stress is on sensitivity to individual needs and rates of development. 


\section{References}

Achilles, C. M. (1999). Let's Put Kids First, Finally. California: Corwin Press.

Anderson, L. W. (2000). Why should reduced class size lead to increased student achievement? In M. C. Wang and J. D. Finn (Eds.) How Small Classes Help Teachers Do Their Best. Philadelphia: Temple University Center for Research in Human Development.

Avon Reception Entry Assessment (1996). Avon Education Department and the Institute of Education.

Blatchford, P. (in press, a) The Class Size Debate: Is Small Better? Open University Press

Blatchford, P. (in press, b) A systematic observational study of teachers' and pupils' behaviour in large and small classes. Learning and Instruction

Blatchford, P., Baines, E., Kutnick, P., \& Martin, C. (2001) Classroom contexts: connections between class size and within class grouping. British Journal of Educational Psychology, 71, 283-302

Blatchford, P., Bassett, P., Goldstein, H., \& Martin, C. (in preparation) Is small better?: Class size, academic progress and classroom processes in children aged 5-7 years

Blatchford, P., Edmonds, S., \& Martin, C. (in press) Class size, pupil attentiveness and peer relations. British Journal of Educational Psychology

Blatchford, P., Galton, M., Kutnick, P., \& Baines, E. (in press) Improving the effectiveness of pupil group work in classrooms. In Blatchford.,P \& Kutnick, P. (Eds.) Special Edition on Group Work in Classrooms International Journal of Educational. $\underline{\text { Research }}$

Blatchford, P., Goldstein, H., Martin, C., \& Browne, W. (2002) A study of class size effects in English School reception classes. British Educational Research Journal, 28, 2, $169-185$

Blatchford, P., Goldstein, H. and Mortimore, P. (1998) Research on class size effects: a critique of methods and a way forward. International Journal of Educational Research, $29,691-710$

Blatchford, P., Kutnick, P., Clark, H., MacIntyre, H., \& Baines, E. (2001) The Nature and Use of Within Class Groupings in Secondary Schools. End of Award Report to ESRC, Project Ref: R000238172

Blatchford, P., Martin, C., Moriarty, V., Bassett, P., \& Goldstein, H. (2002) Pupil Adult Ratio Differences and Educational Progress over Key Stage 1. Final Report to the DfES 
Blatchford, P., Moriarty, V., Edmonds, S., \& Martin, C. (2002) Relationships between class size and teaching: a multi-method analysis of English infant schools. American Educational Research Journal, 39, 1, pp. 101-132

Bronfenbrenner, U. (1979). The Ecology of Human Development. Cambridge, MA: Harvard University Press.

Creemers, B. (1994). The Effective Classroom. London: Cassell

Doyle, W. (1986). Classroom organization and management. In Wittrock, M. C. (ed.) Handbook of Research on Teaching (Third Edition). New York: Macmillan.

Education at a Glance - OECD Indicators 2002. OECD Publications, Paris.

Finn, J.D. \& Achilles, C.M. (1999) Tennessee's Class Size Study: findings, implications, misconceptions. Educational Evaluation and Policy Analysis, Vol. 21, No.2, 97-109.

Finn, J.D., Gerber, S.B., Farber, S.L., and Achilles, C.M. (2000) Teacher aides: an alternative to small classes? In Wang and Achilles Eds

Galton et al 1996

Goldstein, H. (1995). Multilevel Statistical Models. London: Edward Arnold.

Goldstein, H. \& Blatchford, P. (1998) Class size and educational achievement: a review of methodology with particular reference to study design. British Educational Research Journal, 24, 3, 255-268

Evertson, C.M., \& Randolph, C.H. (1989). Teaching practices and class size: a new look at an old issue. Peabody Journal of Education, 67, 1, 85-105.

Hanushek, E.A. (1999) Some findings from an independent investigation of the Tennessee STAR experiment and from other investigations of class size effects. Educational Evaluation and Policy Analysis, 21, 2, 143-163.

Kounin, J.S. \& Gump, P.V. (1974), Signal systems of lesson settings and the taskrelated behaviour of pre-school children. Journal of Educational Psychology, 66, 4, 554-562.

Kutnick, P., Blatchford, P., \& Baines, E. (2002) Pupil groupings in Primary School classrooms: sites for learning and social pedagogy? British Educational Research Journal, 28, 2, 187-206

Ladd, G. W \& Profilet, S.M. (1996) Child Behavior Scale; A Teacher-Report Measure of Young Children's Aggressive, Withdrawn and Prosocial Behaviors. Developmental Psychology, 32, 6, 1008-24.

Moriarty, V., Edmonds, S., Blatchford, P., \& Martin, C. (2001) Teaching young children: perceived satisfaction and stress. Educational Research, 43, 1, 33-46 
Mortimore, P. and Blatchford, P. (1993) The Issue of Class Size National Commission on Education, Briefing No. 12, March

Nye B., Hedges, L.V. \& Konstantopoulos, S. (2000). The effects of small classes on academic achievement: the results of the Tennessee class size experiment, American Educational Research Journal, 37, 1, 123-151.

OFSTED (1995). Class size and the Quality of Education. London: HMSO.

Pellegrini, A. \& Blatchford, P. (2000) The Child at School: Interactions with Peers and Teachers London: Edward Arnold.

Reading Progress Test (2000). London: Hodder and Stoughton

Shulman, L. S. (1986). Paradigms and research programs in the study of teaching. In Wittrock, M. C. (ed.) Handbook of research on teaching (Third edition). New York. Macmillan.

Slavin, R. E. (1989). Class size and student achievement: Small effects of small classes. Educational Psychologist, 24, 99-110.

Tizard, B., Blatchford, P., Burke, J., Farquhar, C. \& Plewis, I. (1988) Young Children at School in the Inner City. Hove: Lawrence Erlbaum Associates.

Wang, M.C., \& Finn, J.D. (2000) Small classes in practice: the next steps. In Wang and Finn (2000) (Eds.) How Small Classes Help Teachers Do Their Best. Philadelphia: Temple University Center for Research in Human Development.

Young, D. (1989). Group Reading Test. Hodder \& Stoughton Educational, London.

Young, D. (1996). Group Mathematics Test. Hodder \& Stoughton Educational, London. 
